\title{
OPEN Significance of genetic modifiers of hemoglobinopathies leading towards precision medicine
}

\author{
Priya Hariharan, Manju Gorivale, Pratibha Sawant, Pallavi Mehta \& Anita Nadkarni ${ }^{\bowtie}$
}

Hemoglobinopathies though a monogenic disorder, show phenotypic variability. Hence, understanding the genetics underlying the heritable sub-phenotypes of hemoglobinopathies, specific to each population, would be prognostically useful and could inform personalized therapeutics. This study aimed to evaluate the role of genetic modifiers leading to higher $\mathrm{HbF}$ production with cumulative impact of the modifiers on disease severity. 200 patients ( $100 \beta$-thalassemia homozygotes, 100 Sickle Cell Anemia), and 50 healthy controls were recruited. Primary screening followed with molecular analysis for confirming the $\beta$-hemoglobinopathy was performed. Co-existing $\alpha$-thalassemia and the polymorphisms located in 3 genetic loci linked to $\mathrm{HbF}$ regulation were screened. The most remarkable result was the association of SNPs with clinically relevant phenotypic groups. The $y$-globin gene promoter polymorphisms [- $158 \mathrm{C} \rightarrow \mathrm{T},+25 \mathrm{G} \rightarrow \mathrm{A}], \mathrm{BCL11A}$ rs $1427407 \mathrm{G} \rightarrow \mathrm{T},-3 \mathrm{bp}$ HBS1L-MYB rs66650371 and rs9399137 $\mathrm{T} \rightarrow \mathrm{C}$ polymorphisms were correlated with higher $\mathrm{HbF}$, in group that has lower disease severity score $(P<0.00001)$, milder clinical presentation, and a significant delay in the age of the first transfusion. Our study emphasizes the complex genetic interactions underlying the disease phenotype that may be a prognostic marker for predicting the clinical severity and assist in disease management.

$\beta$-Thalassemia and sickle cell anemia (SCA) form a major health burden in India as they cause a high degree of morbidity, moderate to severe hemolytic anemia with the carrier frequency varying from 3 to $17 \%$ among different population groups of India ${ }^{1}$. Both the diseases are caused by mutations in the $\beta$-globin gene and are inherited as an autosomal recessive single gene disorder. However, despite this apparent genetic simplicity, both the disorders display a remarkable spectrum of phenotypic severity. In $\beta$-thalassemics, the primary determinant of disease severity is the type of $\beta$-globin gene mutation that the patient inherits. Severe $\beta$-thalassemia mutation $\left(\beta^{0} / \beta^{+}\right)$may completely down-regulate $\beta$-globin chain synthesis. However, milder $\beta^{++}$mutations, present in the conserved $5^{\prime} \beta$-globin promoter region and $3^{\prime}$ untranslated region, may alter the mRNA expression, leading to the moderate synthesis of the $\beta$-globin chain ${ }^{2}$. It has been observed that patients inheriting the same $\beta$-globin gene mutations, display phenotypic heterogeneity. Thus, the clinical variability observed among the patients prompted the search for the additional genetic modulators of these diseases.

Several modifier genes have been identified which influence the severity of hemoglobinopathies. The most common secondary modifier is the co-inheritance of $\alpha$-thalassemia and the elevated levels of fetal hemoglobin $(\mathrm{HbF})$, both of which directly reduce the globin chain imbalance. An interacting combination of $\alpha$-thalassemia with hemoglobinopathy has been shown to alleviate the severity by reducing the intracellular precipitation of free alpha-globin chains in $\beta$-thalassemia and by reducing HbS concentration in SCA patients ${ }^{3,4}$.

The possibility that the severity of hemoglobinopathies could be reduced by induction of HbF was realized as the symptoms of hemoglobinopathies are observed after 6 months of age after the birth when there is a gradual reduction in the $\mathrm{HbF}$ levels. Thus, the study of other secondary mechanisms related to the sustained production of $\mathrm{HbF}$ in adult life may be important. With the advent of genome-wide association studies, recently several unlinked genetic factors have been identified which elevate the $\mathrm{HbF}$ levels ${ }^{5}$. Four major quantitative trait loci (QTLs): the beta globin gene (HBB) locus, the B-cell lymphoma/leukemia 11A (BCL11A)gene, the HBS1 Like Translational GTPase-MYB Proto-Oncogene (HBSB1L-cMYB) inter-region along with Krueppel-like factor 1 (KLF1) gene variations bring about $20-50 \%$ variation in $\mathrm{HbF}$ levels in hemoglobinopathy patients ${ }^{5}$. Thus, in this study, we have screened for the presence of primary and secondary modifiers in hemoglobinopathy patients and have analysed the cumulative effect of these modifiers on the phenotypic variability in the patient group. 


\section{Materials and methods}

Selection of patients and healthy controls. The study was approved by the National Institute of Immunohaematology-Institutional Ethics Committee. All methods were performed in accordance with relevant guidelines and regulation. Unrelated $100 \beta$-thalassemia homozygous and 100 SCA patients were selected for this study. As this study aimed to determine the correlation between genetic modifiers of the $\beta$-hemoglobinopaties with the phenotypic manifestations of the patients, among the $\beta$-thalassemia homozygous group, 50 patients with severe phenotype ( $\beta$-thalassemia major) and 50 patients with milder phenotype ( $\beta$-thalassemia intermedia) were specifically selected. 50 unrelated healthy adult blood donors with normal hematological indices, with no transfusion history and medication, were randomly selected. The blood samples were collected in K2 EDTA vacutainers after informed consent.

Primary screening and molecular analysis. Primary screening involved complete blood count analysis and the concentration of different hemoglobin fractions was quantified on BioRad Variant II high-performance liquid chromatography.

Molecular analysis of the $\beta$-globin gene was first carried out to confirm the hemoglobinopathy status in the patient samples by covalent reverse dot blot hybridization (CRDB), amplification refractory mutation system-polymerase chain reaction (AMRS PCR), or by direct DNA sequencing ${ }^{6}$. a-globin gene deletions were detected by multiplex PCR ${ }^{7}$. The $\gamma$-globin promoter region [NC_000011.9 (5250415-5249612)] was screened by direct DNA sequencing. Five BCL11A polymorphisms which showed the highest correlation with $\mathrm{HbF}$ levels [rs11886868C $\rightarrow \mathrm{T}\left(\mathrm{NC} \_000002.12: \mathrm{g} .60493111 \mathrm{C}>\mathrm{T}\right)$ [Assay ID: C__11363852_10], rs7557939 A $\rightarrow$ G] (NC_000002.12:g.60494212G > A) [Assay ID: C___2069774_10], rs4671393 A $\rightarrow$ G NC_000002.12:g.60493816A > G [Assay ID: C__25926414_10], rs1427407 G $\rightarrow$ T (NC_000002.12:g.60490908T > G) [Primers: Common F: 5'ATGTGTTCCCAATGAGTTTC3', Reverse Normal allele: 5'GTTCAAGTAGATATCAGAAGGGAGA3', Reverse Mutant allele: 5'GTTCAAGTAGATATCAGAAGG GAGC3'] and rs7606173 G $\rightarrow$ C (NC_000002.12:g.60498316G > C) [Primers: Forward Normal allele: 5'GCTGGG CACAGCCTTGAC3', Forward Mutant allele: 5'GCTGGGCACAGCCTTGAG3', Common Reverse: 5'CTAGGA AGGGAAGTGGGTAT3'] were analyzed by real-time SNP genotyping ${ }^{8}$ and by ARMS PCR. 2 polymorphisms in HBS1L-MYB intergenic region [rs66650371 Intact 'TAC' $\rightarrow$ Deletion 'TAC' (NC_000006.12:g.135097497_1 35097499del) [Primers for detecting normal allele: Forward primer: 5'TCACTCTGGACAGCAGATGTTACT AT3', Reverse primer: 5'CTCAGTGATGGTATTTCTGGAGAC3', Primers for detecting mutant allele: Forward primer: 5'AGCCCGTCCAGACACTCATTGTT3', Reverse primer: 5'GCCCTGATAACATTTTGTGGTTTT CATTTAACAT3'], rs9399137 T $\rightarrow$ C (NC_000006.12:g.135097880T $>$ C)] were screened by ARMS PCR and by DNA sequencing respectively.

The patients were clinically evaluated and the disease severity score was calculated based on the detailed clinical history of the patient ${ }^{9,10}$. Linkage disequilibrium analysis was performed by using Haploview software. (https://www.broadinstitute.org/haploview/haploview).

Statistical analysis. Statistical analysis of the data was performed using GraphPad version 6.01 software (Graph Pad Prism Inc, California, U.S.A). The hematological indices among different patient groups and normal controls are represented as mean \pm standard deviation (SD). Fischer extract test was used to compare the polymorphism distribution among the patients and the control groups. The comparison of the quantitative variables among the groups and between differing genotypes was carried out by unpaired non-parametric Mann-Whitney $\mathrm{U}$ test. The P-value $\leq 0.05$ was considered to be statistically significant. Generalized Multifactor Dimensionality Reduction (GMDR) software version beta 0.9 was used to analyse the interaction among the SNPs in different patient groups. The Kaplan Meier survival curve analysis was performed to determine the age of presentation by considering the transfusion free survival among the patient groups.

Ethics approval. The study was approved by the National Institute of Immunohaematology-Institutional Ethics Committee.

Consent to participate. Informed consent was obtained from all individual participants included in the study.

\section{Results}

On the basis of clinical history, the $\beta$-thalassemia patients were classified into a severe group (50 Thalassemia major: TM) and milder group (50 Thalassemia Intermedia: TI).

3 parameters were considered for clinical analysis in both the hemoglobinopathy patient group. These included the age of presentation, frequency of blood transfusion, and organomegaly. As expected, the patients in the $\beta$-thalassemia major group had an early age of presentation (9.2 \pm 2.7 months $)$ and recurrent blood transfusion requirement ( $14.8 \pm 4.0$ times/year) as compared to the milder $\beta$-thalassemia intermedia group (mean age: $4.5 \pm 3.3$ years and transfusion frequency: $2.5 \pm 3.3$ times/year). In the SCA, the mean age of presentation was found to be $6.3 \pm 5.2$ years. Further to know the contribution of $\mathrm{HbF}$ levels in the clinical presentation of the SCA patients, they were divided into two groups considering the median HbF level of $17.4 \%$. It was observed that SCA patients with $\mathrm{HbF}$ levels $\leq 17.4 \%$ showed higher mean transfusion frequency ( $3.3 \pm 5.5$ times/year) as compared to patients with $\mathrm{HbF}>17.4 \%$ ( $1.7 \pm 5.4$ times/year). Hepatosplenomegaly was pronounced in $\beta$-thalassemia intermedia group as against thalassemia major (P: 0.001). Also, in SCA patients, hepatosplenomegaly was observed. 


\begin{tabular}{|l|l|l|l|l|}
\hline \multirow{2}{*}{ Parameters } & \multicolumn{2}{|l|}{$\boldsymbol{\beta}$-thalassemia Homozygous } & \multicolumn{2}{l|}{ Sickle cell anemia patients } \\
\cline { 2 - 5 } & $\begin{array}{l}\boldsymbol{\beta} \text {-thalassemia major } \\
\mathbf{n = 5 0}\end{array}$ & $\begin{array}{l}\boldsymbol{\beta} \text {-thalassemia intermedia } \\
\mathbf{n = 5 0}\end{array}$ & $\begin{array}{l}\text { HbF level: } \leq \mathbf{1 7 . 4 \%} \\
\mathbf{n = 5 0}\end{array}$ & $\begin{array}{l}\text { HbF level : } \mathbf{1 7 . 4 \%} \\
\mathbf{n}=\mathbf{5 0}\end{array}$ \\
\hline Mean \pm SD & $9.2 \pm 2.7$ months & $4.5 \pm 3.3$ years & $5.2 \pm 4.9$ & $7.1 \pm 5.5$ \\
\hline Age of presentation & $2.5 \pm 3.3$ & $3.3 \pm 5.5$ & $1.7 \pm 5.4$ \\
\hline $\begin{array}{l}\text { Blood transfusion per year (no. of } \\
\text { times) }\end{array}$ & $14.8 \pm 4.0$ & $4.6 \pm 3.5$ & $5.3 \pm 3.1$ & \\
\hline Hepatomegaly $(\mathrm{cm})^{\mathrm{a}}$ & $2.7 \pm 2.9$ & $6.5 \pm 3.6$ & $6.8 \pm 5.1$ \\
\hline Splenomegaly $(\mathrm{cm})^{\mathrm{b}}$ & $4.7 \pm 1.7$ &
\end{tabular}

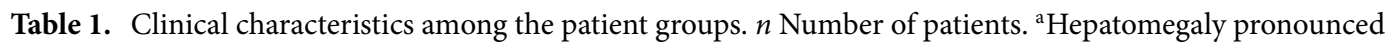
in thalassemia intermedia and Sickle cell anemia patients. ${ }^{b}$ Splenomegaly in thalassemia intermedia and Sickle cell anemia patients.

\begin{tabular}{|c|c|c|c|c|c|c|c|}
\hline \multirow[b]{2}{*}{ Parameters } & \multirow{2}{*}{$\begin{array}{l}\text { Controls } \\
\text { Mean } \pm \text { SD }\end{array}$} & \multicolumn{3}{|c|}{$\beta$-thalassemia homozygous } & \multicolumn{3}{|c|}{ Sickle cell anemia patients } \\
\hline & & $\begin{array}{l}\text { TM, n: } 27 \\
\text { Mean } \pm \text { SD }^{a}\end{array}$ & $\begin{array}{l}\text { TI, n: } 50 \\
\text { Mean } \pm \text { SD }\end{array}$ & $\begin{array}{l}{ }^{*} \text { P value } \\
95 \% \mathrm{CI}\end{array}$ & $\begin{array}{l}\mathrm{HbF} \leq 17.4 \% \\
\text { n: } 50 \\
\text { Mean } \pm \text { SD }\end{array}$ & $\begin{array}{l}\mathrm{HbF}>17.4 \% \\
\mathrm{n}: 50 \\
\text { Mean } \pm \text { SD }\end{array}$ & $\begin{array}{l}{ }^{* *} \mathbf{P} \text { value } \\
95 \% \mathrm{CI}\end{array}$ \\
\hline $\operatorname{RBCs}\left(10^{6} / \mu \mathrm{L}\right)$ & $4.6 \pm 0.6$ & $2.8 \pm 0.70$ & $3.5 \pm 0.69$ & $<0.0001$ & $3.1 \pm 0.9$ & $3.1 \pm 0.9$ & 0.5 \\
\hline $\mathrm{Hb}(\mathrm{g} / \mathrm{dL})$ & $13.5 \pm 2.04$ & $5.4 \pm 1.17$ & $7.8 \pm 1.4$ & $<0.0001$ & $8.1 \pm 2.1$ & $9.1 \pm 2.5$ & 0.03 \\
\hline $\mathrm{MCV}(\mathrm{fL})$ & $83.9 \pm 4.2$ & $75.1 \pm 17.3$ & $70.7 \pm 7.8$ & 0.92 & $79.4 \pm 12.0$ & $84.0 \pm 10.6$ & 0.04 \\
\hline $\mathrm{MCH}(\mathrm{pg})$ & $28.9 \pm 4.2$ & $24.4 \pm 5.2$ & $22.8 \pm 3.4$ & 0.28 & $26.4 \pm 4.4$ & $29.2 \pm 3.8$ & 0.008 \\
\hline $\mathrm{MCHC}(\mathrm{g} / \mathrm{dL})$ & $34.5 \pm 1.5$ & $31.6 \pm 3.5$ & $32.2 \pm 1.9$ & 0.18 & $33.2 \pm 2.1$ & $34.8 \pm 2.5$ & 0.0003 \\
\hline RDW (\%) & $13.85 \pm 1.5$ & $32.8 \pm 9.8$ & $30.8 \pm 5.9$ & 0.36 & $22.8 \pm 4.6$ & $20.8 \pm 6.3$ & 0.0016 \\
\hline Platelets $\left(10^{3} / \mu \mathrm{L}\right)$ & $291.7 \pm 38.0$ & $333 \pm 246.8$ & $370.8 \pm 269$ & 0.23 & $349.7 \pm 211.1$ & $221 \pm 115.6$ & 0.0002 \\
\hline $\mathrm{HbA}_{2}(\%)$ & $2.6 \pm 0.2$ & $3.6 \pm 1.5$ & $3.4 \pm 1.9$ & 0.08 & $3.0 \pm 0.5$ & $2.9 \pm 1.1$ & 0.007 \\
\hline HbF (\%) & $0.31 \pm 0.2$ & $65.6 \pm 36.3$ & $66.3 \pm 34.2$ & 0.46 & $12.7 \pm 3.7$ & $26.4 \pm 7.1$ & $<0.0001$ \\
\hline F-cells (\%) & $2.4 \pm 0.5$ & $67.1 \pm 26.01$ & $68.0 \pm 24.1$ & 0.81 & $31.8 \pm 18.6$ & $43.2 \pm 18.2$ & 0.06 \\
\hline HbS (\%) & - & - & - & - & $74.1 \pm 11.7$ & $67.5 \pm 9.4$ & $<0.0001$ \\
\hline
\end{tabular}

Table 2. Hematological analysis among the patient and the control groups. ${ }^{\star} \mathrm{P}$ value calculated among the $\beta$-thalassemia homozygous groups, ${ }^{\star *} \mathrm{P}$ value calculated among the SCA patient groups. The P value was calculated using unpaired non parametric Mann-Whitney U test. ${ }^{a}$ At the time of testing 23 TM patients were on regular transfusions, hence these patients were excluded from hematological analysis.

The detailed clinical analysis among the patient groups is shown in Table 1 . The hematological parameters of the patient groups are shown in Table 2.

Molecular analysis of the $\beta$-globin gene showed that IVS $1-5 \mathrm{G} \rightarrow \mathrm{C}(\mathrm{HBB}: \mathrm{c} .92+5 \mathrm{G}>\mathrm{C})$ was the commonest mutation encountered in both the $\beta$-thalassemia homozygous group (TM: $32 \%$, TI: $28 \%$ ). The six common Indian mutations [IVS 1-5 $(\mathrm{G} \rightarrow \mathrm{C}), 619$ bp deletion $(\mathrm{NG}$ _000007.3:g.71609_72227del619), IVS 1-1 G $\rightarrow$ T (HBB:c.92+1G>T), codons 8/9+G (HBB:c.27_28insG), codon $15 \mathrm{G} \rightarrow \mathrm{A}$ (HBB:c.47G > A), codons 41/42-CTTT (HBB:c.126_129delCTTT)] accounted for 82.5\% of molecular lesions (TM: 44.5\%, TI: 38\%). It was observed that the overall prevalence of milder mutations was higher in TI patients (8.0\%) as compared to TM patients (1.0\%, P: 0.07) (Supplementary Table 1).

As co-inheritance of $\alpha$-thalassemia is a well-known disease modifier of $\beta$-thalassemia and SCA, the presence of $\alpha$-globin-gene deletions was screened in the patient groups. A much higher prevalence of single alpha globin gene deletions was observed in SCA patients (51.0\%). Among the $\beta$-thalassemia homozygotes, the $\beta$-thalassemia intermedia showed a higher prevalence $(26.0 \%)$ of $\alpha$-globin gene deletions as compared to $\beta$-thalassemia major (20.0\%). (P: 0.47) (Supplementary Table 2).

The second powerful modifier of disease severity in hemoglobinopathy patients is elevated HbF levels. Hence the polymorphisms located in the three loci linked to raised HbF levels: $\gamma$-globin promoter region, BCL11A and HBSL1-MYB intergenic region were analysed in this study.

In the ${ }^{\mathrm{G}} \gamma$ globin promoter region, the XmnI polymorphism residing in the $-158 \mathrm{C} \rightarrow \mathrm{T}(\mathrm{HBG} 2 \mathrm{c}$ - $-211 \mathrm{C} \rightarrow \mathrm{T})$ position was only detected. In the $\beta$-thalassemia homozygous group, the homozygosity for the mutant $\mathrm{T}$ allele [T/T, Xmn I+/+] was significantly higher in TI (44.0\%) as compared to TM (28.0\%), (P: 0.01).Similarly, in SCA patients, $94 \%$ of the patients were homozygous for the T allele. As thalassemia major patients were on recurrent transfusion, the genotypes could not be compared with the HbF levels, however, in thalassemia intermediates, the TT [XmnI: $+/+]$ genotype was found to be significantly associated with raised HbF levels $(79.1 \% \pm 29.0, \mathrm{P}$ : $0.04)$ as compared to the CC [XmnI: $-/-]$ genotype (53.08\% \pm 35.9$)$. (Fig. 1A).

In the ${ }^{\mathrm{A}} \gamma$-globin promoter region, $+25(\mathrm{G} \rightarrow \mathrm{A})(\mathrm{HBG1}: \mathrm{c} .-29 \mathrm{G}>\mathrm{A})$ variation was detected and A allele was found to be the variant allele. The A allele was found to be significantly higher in the TI group as compared to 


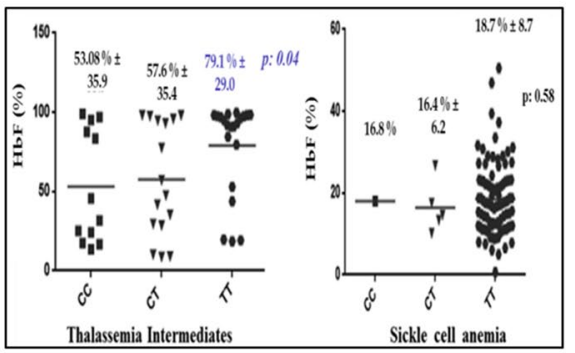

A

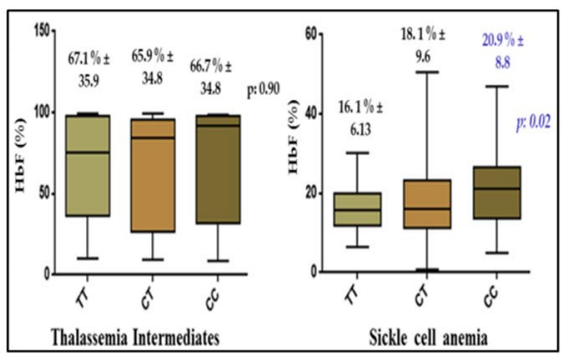

D

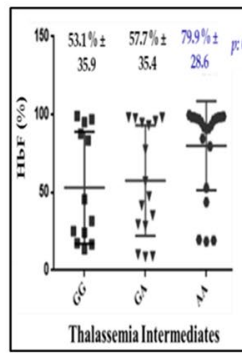

Thalassemia Intermediates

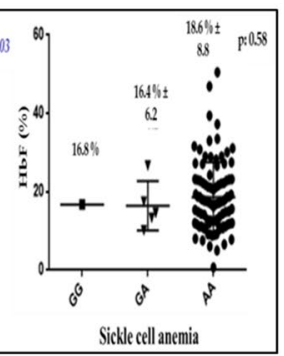

B



C

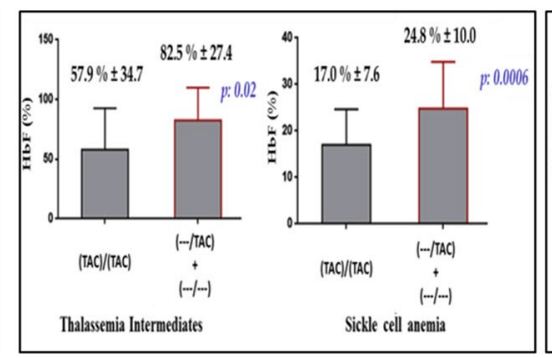

E

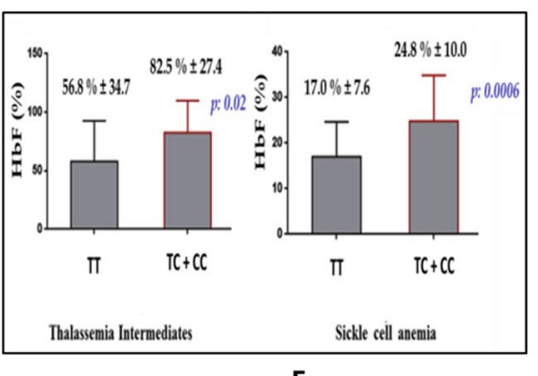

$\mathbf{F}$

Figure 1. Association of the SNP genotypes with $\mathrm{HbF}$ levels in $\beta$-hemoglobinopathy patients. (A) XmnI polymorphism: $-158(\mathrm{C} \rightarrow \mathrm{T}),(\mathbf{B})+25(\mathrm{G} \rightarrow \mathrm{A})$ polymorphism, $(\mathrm{C}) \mathrm{rs} 1427407(\mathrm{G} \rightarrow \mathrm{T})$ polymorphism, $(\mathrm{D})$ $\mathrm{rs} 11886868(\mathrm{C} \rightarrow \mathrm{T}),(\mathrm{E}) \mathrm{rs66650371}$ (Intact TAC $\rightarrow 3$ bp deletion) polymorphism, $(\mathbf{F})$ rs9399137 $(\mathrm{T} \rightarrow \mathrm{C})$ polymorphism.

TM (P: 0.005). Also, the A allele in $\beta$-thalassemia intermediates, was significantly associated with increased $\mathrm{HbF}$ levels (79.9\% $\pm 28.6, \mathrm{P}: 0.03)$. In SCA patients, $94 \%$ of the patients were homozygous for the A allele, an observation similar to the XmnI polymorphism (Fig. 1B).

Among the 5 intronic polymorphisms in the BCL11A gene screened, the mutant $\mathrm{T}$ allele of $\mathrm{rs} 1427407(\mathrm{G} \rightarrow \mathrm{T})$ polymorphism, was significantly higher in the $\beta$-thalassemia intermedia group as compared to the thalassemia major group (P: 0.002, OR 5.6, 1.84-17.22). In SCA patients the $\mathrm{T}$ allele was found to be significantly associated with raised $\mathrm{HbF}$ levels $(\mathrm{HBF}>17.4 \%$ (P: 0.003, OR 3.14, 1.46-6.75) as compared to the other group. The T allele was also found to be significantly associated with $\mathrm{HbF}$ levels in both the patient groups $(\mathrm{P}<0.05)$ (Fig. $1 \mathrm{C})$.

In the sickle cell anemia patients, the $\mathrm{C}$ allele of $\mathrm{rs} 11886868 \mathrm{C} \rightarrow \mathrm{T}$ polymorphism was found to be significantly associated with increased HbF levels (P: 0.02, HbF: 20.9\% \pm 8.8) (Fig. 1D). Among the HBS1L-MYB intergenic polymorphisms, the deletional allele of rs66650371 (Intact TAC $\rightarrow$ Deletion- 'TAC') polymorphism and the $\mathrm{C}$ allele of rs9399137 $(\mathrm{T} \rightarrow \mathrm{C}$ ) were found to be significantly present in the milder $\beta$-hemoglobinopathy patients. As reported in earlier studies these 2 polymorphisms were found to be in complete linkage disequilibrium. The minor alleles of these polymorphisms were found to be significantly associated with the HbF levels (Fig. 1E,F). Table 3 gives a detailed analysis of the allelic frequency of these polymorphisms determined among the patient and the control group.

The linkage disequilibrium plot showed that the $+25(\mathrm{G} \rightarrow \mathrm{A})$ polymorphism in ${ }^{\mathrm{A}} \gamma$-globin gene and the XmnI polymorphism in the ${ }^{G} \gamma$-globin are highly linked (Linkage Disequilibrium coefficient $D^{\prime}$ : 93). Also, the SNPs rs11886868 $(\mathrm{C} \rightarrow \mathrm{T})$ and $\mathrm{rs} 7557939(\mathrm{~A} \rightarrow \mathrm{G})$ in the BCL11A intronic region, are strongly linked $\left(\mathrm{D}^{\prime}: 88\right)$ with each other (Fig. 2).

Further, the best SNP models accompanied by the lowest prediction error (Testing balance accuracy), the highest CVC, and the P-value of significant level were calculated. The results revealed a cumulative effect of the mutant alleles of the 3 SNPs $-158(\mathrm{C} \rightarrow \mathrm{T})$, rs11886868 $(\mathrm{C} \rightarrow \mathrm{T})$, and rs1427407 $(\mathrm{G} \rightarrow \mathrm{T})$ significantly higher in $\beta$-thalassemia intermedia patients, and as the best SNP model with testing balance accuracy of $74.9 \%$ and crossvalidation consistency of $9 / 10$. Further gene-gene interaction studies showed a synergistic effect may coexist among these SNPs in elevating the HbF level (Fig. 3A). Similarly among the SCA patients, gene-gene interaction between the mutant alleles of rs66650371 and rs1427407 were found to be significantly higher in the sickle cell anemia patients with $\mathrm{HbF}$ levels $>17.4 \%$ with a testing balance accuracy $66.0 \%$ and cross-validation consistency 10/10 (Fig. 3B). The generation of GMDR models for determining the most influential SNPs among the 9 SNPs studied in the patient groups is shown in Supplementary Table 3.

The presence of ameliorating alleles may significantly delay the age of presentation and transfusion requirement in $\beta$-hemoglobinopathy patients. Hence, for the analysis we included both primary modifiers (the type of $\beta$-globin gene mutation in $\beta$-thalassemia patients) and secondary modifiers: $\alpha$-globin genotype and the HbF modulators [ $\gamma$-globin promoter variations, BCL11A, MYB and KLF1 variations (the KLF1 data from our previous published paper $)^{11}$. Among the SCA patients, a strong negative correlation was observed between the $\mathrm{HbF}$ levels and the disease severity score. (Pearson correlation coefficient $\mathrm{r}:-0.7, \mathrm{P}<0.00001$ ) The patients inheriting the higher numbers of modulating allele showed significantly elevated HbF levels (mean HbF: $21.9 \% \pm 9.8$ ) 


\begin{tabular}{|c|c|c|c|c|c|c|c|c|}
\hline \multirow{2}{*}{\multicolumn{2}{|c|}{ Allelic frequencies (N: 100) }} & \multirow[b]{2}{*}{$\begin{array}{l}\text { Controls } \\
\mathrm{n}: 50\end{array}$} & \multicolumn{2}{|c|}{$\begin{array}{l}\beta \text {-Thalassemia } \\
\text { homozygous }\end{array}$} & \multicolumn{2}{|c|}{$\begin{array}{l}\text { Sickle cell anemia } \\
\text { patients }\end{array}$} & \multirow[b]{2}{*}{$\begin{array}{l}{ }^{*} \mathbf{P} \text { value/Odds Ratio } \\
95 \% \text { CI }\end{array}$} & \multirow[b]{2}{*}{$\begin{array}{l}\text { **P value/Odds Ratio } \\
95 \% \text { CI }\end{array}$} \\
\hline & & & $\begin{array}{l}\text { TM } \\
\mathbf{n}: 50\end{array}$ & $\begin{array}{l}\text { TI } \\
\text { n:50 }\end{array}$ & $\begin{array}{l}\mathrm{HbF} \\
\leq 17.4 \% \\
\mathrm{n}: 50\end{array}$ & $\begin{array}{l}\text { HbF } \\
>17.4 \% \\
\mathrm{n}: 50\end{array}$ & & \\
\hline \multirow{2}{*}{$-158(\mathrm{C} \rightarrow \mathrm{T})$} & $\mathrm{C}$ & 81 & 59 & 41 & 5 & 2 & \multirow{2}{*}{$0.01 / 2.07(1.1-3.6)$} & \multirow{2}{*}{$0.29 / 2.4(0.4-12.7)$} \\
\hline & $\mathrm{T}$ & 19 & 41 & 59 & 95 & 98 & & \\
\hline \multirow{2}{*}{$+25(\mathrm{G} \rightarrow \mathrm{A})$} & G & 81 & 60 & 40 & 5 & 2 & \multirow{2}{*}{$0.005 / 2.2(1.27-3.96)$} & \multirow{2}{*}{$0.29 / 2.4(0.4-12.7)$} \\
\hline & A & 19 & 40 & 60 & 95 & 98 & & \\
\hline \multirow{2}{*}{$\operatorname{rs} 11886868(C \rightarrow T)$} & C & 60 & 55 & 59 & 47 & 57 & \multirow{2}{*}{$0.56 / 1.17(0.67-2.06)$} & \multirow{2}{*}{$0.11 / 1.56(0.89-2.7)$} \\
\hline & $\mathrm{T}$ & 40 & 45 & 41 & 53 & 43 & & \\
\hline \multirow{2}{*}{$\operatorname{rs7557939}(A \rightarrow G)$} & A & 38 & 42 & 43 & 47 & 36 & \multirow{2}{*}{$0.88 / 1.04(0.5-1.8)$} & \multirow{2}{*}{$0.11 / 1.57(0.9-2.7)$} \\
\hline & $\mathrm{G}$ & 62 & 58 & 57 & 53 & 64 & & \\
\hline \multirow{2}{*}{$\operatorname{rs} 4671393(A \rightarrow G)$} & A & 26 & 12 & 18 & 30 & 31 & \multirow{2}{*}{$0.2 / 1.6(0.73-3.5)$} & \multirow{2}{*}{$0.95 / 1.01(0.55-1.85)$} \\
\hline & $\mathrm{G}$ & 74 & 88 & 82 & 70 & 69 & & \\
\hline \multirow{2}{*}{$\operatorname{rs} 1427407(\mathrm{G} \rightarrow \mathrm{T})$} & $\mathrm{G}$ & 95 & 96 & 81 & 89 & 72 & \multirow{2}{*}{$0.002 / 5.6(1.84-17.2)$} & \multirow{2}{*}{$0.003 / 3.14(1.46-6.75)$} \\
\hline & $\mathbf{T}$ & 5 & 4 & 19 & 11 & 28 & & \\
\hline \multirow{2}{*}{$\operatorname{rs7606173}(\mathrm{G} \rightarrow \mathrm{C})$} & $\mathrm{G}$ & 93 & 93 & 95 & 80 & \begin{tabular}{|l|}
78 \\
\end{tabular} & \multirow{2}{*}{$0.55 / 0.69(0.21-2.28)$} & \multirow{2}{*}{$0.72 / 1.1(0.57-2.22)$} \\
\hline & C & 07 & 7 & 5 & 20 & 22 & & \\
\hline \multirow{2}{*}{$\begin{array}{l}\text { rs } 66650371 \\
\text { TAC } \rightarrow 3 \text { base Deletion }\end{array}$} & TAC & 85 & 86 & 75 & 94 & 79 & \multirow{2}{*}{$0.06 / 2.0(0.96-4.12)$} & \multirow{2}{*}{$0.007 / 3.76(1.4-9.8)$} \\
\hline & - & 15 & 14 & 25 & 6 & 21 & & \\
\hline \multirow{2}{*}{ rs9399137 $(\mathrm{T} \rightarrow \mathrm{C})$} & $\mathrm{T}$ & 85 & 86 & 75 & 94 & 79 & \multirow{2}{*}{$0.06 / 2.0(0.96-4.12)$} & \multirow{2}{*}{$0.007 / 3.76(1.4-9.8)$} \\
\hline & $\mathrm{C}$ & 15 & 14 & 25 & 6 & 21 & & \\
\hline
\end{tabular}

Table 3. Genotypic and allelic frequency of the polymorphisms in patient and control group. $n$ Number of patients in each group, $N$ Total number of alleles in each group. ${ }^{\star}$ Thalassemia patients. ${ }^{\star \star}$ SCA patients.

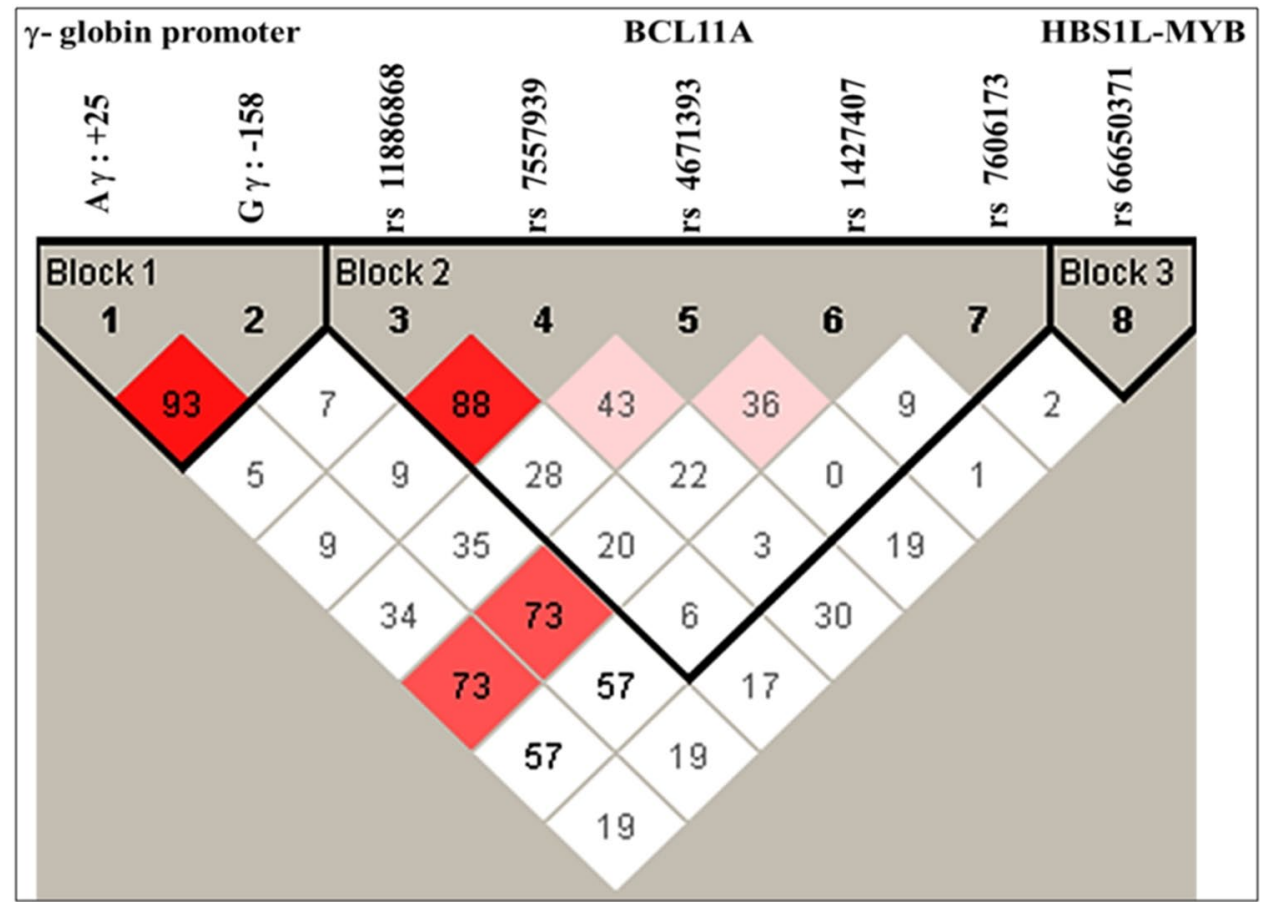

Figure 2. Linkage disequilibrium (LD) plot of the SNPs. It could be observed that the $+25(\mathrm{G} \rightarrow \mathrm{A})$ polymorphism in ${ }^{\mathrm{A}} \gamma$-globin gene and the XmnI polymorphism $(-158 \mathrm{C} \rightarrow \mathrm{T})$ in the ${ }^{\mathrm{G}} \gamma$-globin are highly linked $\left(D^{\prime}: 93\right)$. Also the SNPs rs11886868 $(\mathrm{C} \rightarrow \mathrm{T})$ and $\mathrm{rs} 7557939(\mathrm{~A} \rightarrow \mathrm{G})$ in the BCL11A intronic region, are strongly linked (D': 88) with each other. 


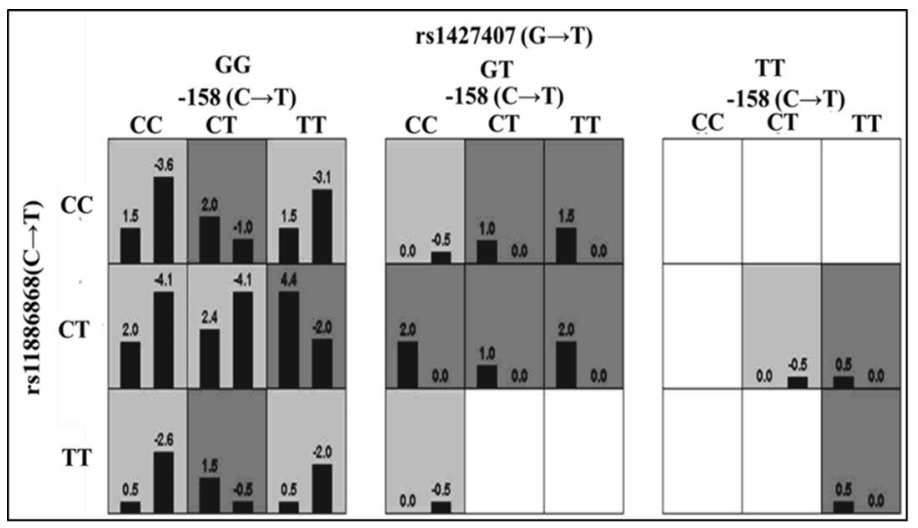

A

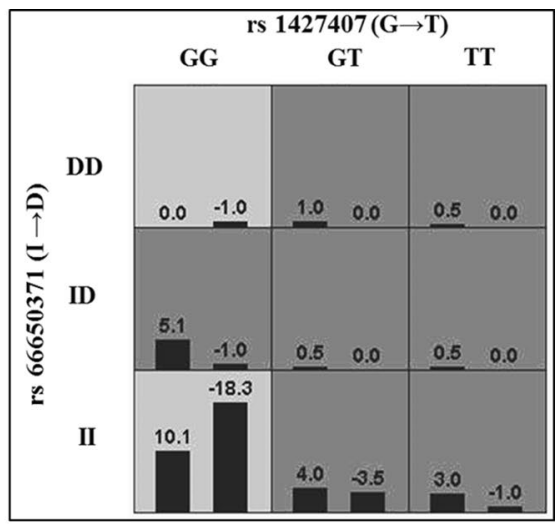

B

Figure 3. SNP tile analysis of gene-gene interaction in $\beta$-hemoglobinopathy patients. The tiles are shaded according to the cumulative scores of both the bars. Here the dark grey tiles represent a positive score (presence of mutant $\mathrm{HbF}$ boosting allele in milder patient group) and the light grey tiles represent a negative score (presence of normal allele in the severe patient group). (A) The mutant alleles of 3 SNPs (XmnI polymorphism, $\mathrm{rs} 11886868(\mathrm{C} \rightarrow \mathrm{T})$ and $\mathrm{rs} 1427407(\mathrm{G} \rightarrow \mathrm{T})$ found to be significantly higher in $\beta$-thalassemia intermedia patients (the left bar) as compared to the $\beta$-thalassemia major patients (right bar). (B) The mutant alleles 2 SNPs [rs66650371 [TAC (I)> deletion of $3 \mathrm{bp}(\mathrm{D})]$ and $\mathrm{rs} 1427407(\mathrm{G} \rightarrow \mathrm{T})$ ] found to be significantly higher in SCA patients with $\mathrm{HbF}$ levels $>17.4 \%$ (left bar) as compared to the SCA patients with $\mathrm{HbF} \leq 17.4 \%$ (right bar).

as compared to patients with less number of disease severity modulating alleles (mean $\mathrm{HbF}: 16.5 \% \pm 7.1$ ). Also showed a significant delay in the age of first transfusion as compared to the other group (Fig. 4A,B). The $\beta$-thalassemia intermedia patients inheriting more number of the disease ameliorating alleles showed elevated $\mathrm{HbF}$ levels (mean $\mathrm{HbF}: 75.1 \% \pm 29.9$ ), with reduced disease severity score (mean DSS: 5.6 ) as compared to patients with lower numbers of disease severity modulating alleles, who had lower HbF levels (mean HbF: $54.1 \% \pm 36.9$ ). Further, when compared to the age of first transfusion, however, no significant difference was observed among the 2 groups (Fig. 4C,D). The Supplementary Table 4 shows the median transfusion free survival and hazard ratio in both the patient groups. The number of modulating alleles, transfusion free survival ratio was inversely associated with the hazard ratio.

\section{Discussion}

Though $\beta$-thalassemia and sickle cell disease are single-gene disorders with prototypical Mendalian inheritance patterns, both the disorders display a wide spectrum of clinical phenotypes. Thus, the search for the genetic modifiers was triggered, as $5-10 \%$ of $\beta$-thalassemia homozygous patients with the same $\beta$-globin gene mutation and sickle cell anemia patients showed a variable pattern of clinical expression ${ }^{12}$.

In this study, we first classified the $\beta$-thalassemia patients according to the clinical severity and then studied the influence of the genetic modifiers. Modell and Berdukas ${ }^{13}$, reported that $60 \%$ of $\beta$-thalassemia homozygous patients presented in the first year of life, these patients were segregated as $\beta$-thalassemia major and $9 \%$ of the $\beta$-thalassemia homozygous patients who presented after 2 years of age, with intermediate clinical severity were classified as $\beta$-thalassemia intermedia ${ }^{13,14}$. A similar observation was made in our study, in which the $\beta$-thalassemia major patients presented early by $9.2 \pm 2.7$ months and the patients in the $\beta$-thalassemia intermedia group had a delayed age of presentation mean of $4.3 \pm 3.3$ years. The $\beta$-thalassemia intermedia patients also showed a significantly higher mean baseline hemoglobin of $7.8 \pm 1.4 \mathrm{~g} / \mathrm{dL}$ as compared to thalassemia major patients. Similarly, another study showed that in $63 \beta$-thalassemia intermedia patients, the hemoglobin values ranged between 7 and $9 \mathrm{~g} / \mathrm{dL}$ with occasional transfusion regimen and splenomegaly ${ }^{15}$. In our study as well, pronounced hepatosplenomegaly was observed in $\beta$-thalassemia intermedia patients as compared to $\beta$-thalassemia major. Mpalampa et al. ${ }^{16}$ considering the mean $\mathrm{HbF}$ cut-off as $10 \%$, in 216 sickle cell anemia patients observed a strong negative correlation of $\mathrm{HbF}$ levels with the total number of transfusions ( $\mathrm{r}=-0.181, \mathrm{P}: 0.004)$, hospitalisations rate $(r=-0.173, P: 0.006)$, and significant positive correlation with the age at diagnosis $(r=0.151, P: 0.013)^{16}$. In the Indian context, Nayak et al. ${ }^{17}$ studied 60 sickle cell anemia patients and observed fewer episodes of painful crises in children with high baseline $\mathrm{HbF}$ level as compared to children with low HbF level ${ }^{17}$. Correspondingly in our study as well, the mean age of diagnosis among 100 SCA patients was found to be $6.3 \pm 5.2$ years which is very much delayed as compared to the patient cohort studied by Mpalampa et al. ${ }^{16}$. This observation could be due to inherently elevated HbF levels in Indian patients mainly due to Arab-Indian haplotype which is a major determinant of $\mathrm{HbF}$ levels in Indian SCA patients ${ }^{18}$. Further, it was observed that the patients with higher $\mathrm{HbF}$ level had a delayed age of presentation ( $7.1 \pm 5.5$ years $)$ with less transfusion requirement and sporadic painful crisis compared to patients with $\mathrm{HbF}$ level $\leq 17.4 \%$ (age of presentation: $5.2 \pm 4.9$ years).

As the $\beta$-thalassemia alleles inherited by the patient act as a primary modulator of the disease severity in $\beta$-thalassemia, Colah et al. ${ }^{19}$ observed that the milder mutations are prevalent in $\beta$-thalassemia intermedia group as compared to severe $\beta$-thalassemia major patients ${ }^{19}$. Similarly in our study, the presence of milder $\beta$-thalassemia alleles were significantly higher in $\beta$-thalassemia intermedia as compared to $\beta$-thalassemia major 


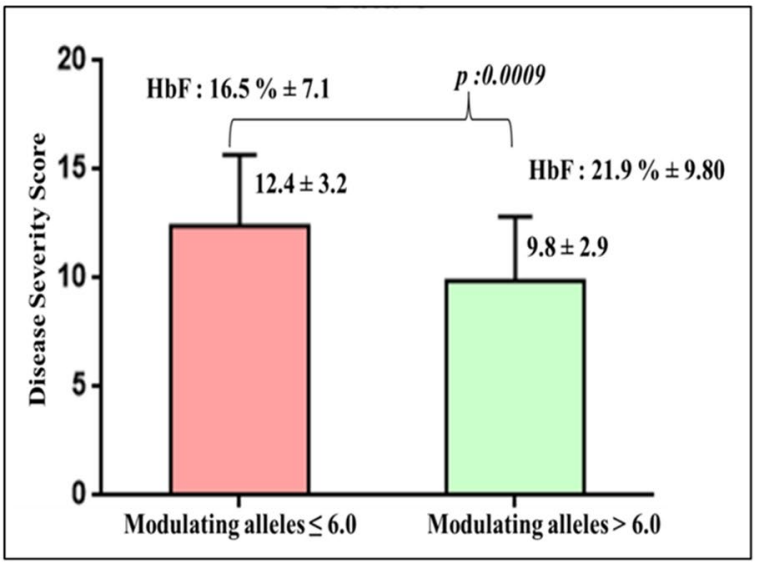

A

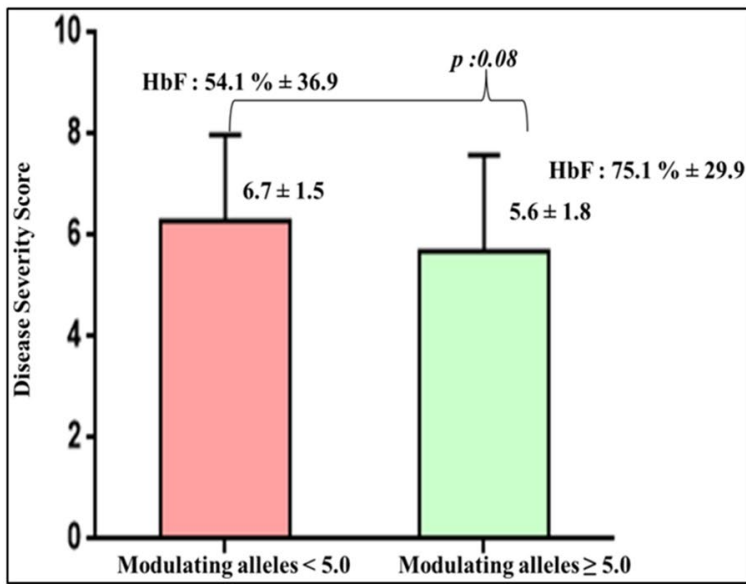

C

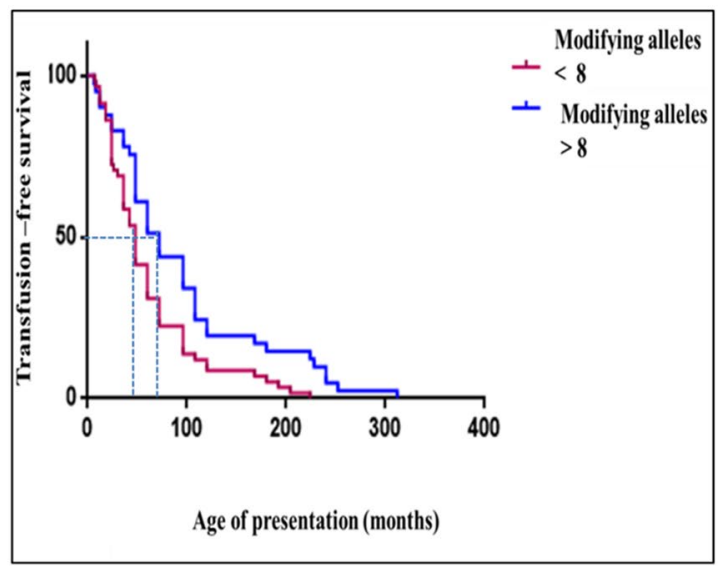

B

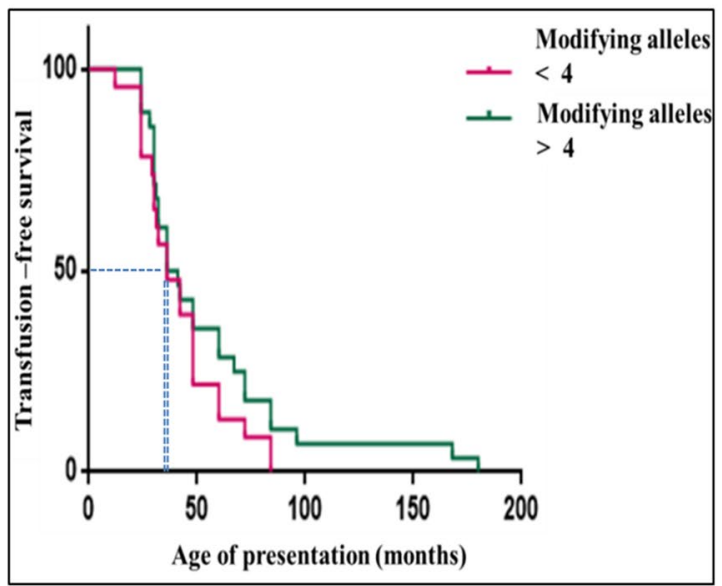

D

Figure 4. Association of disease ameliorating alleles with disease severity in the patients. (A) Depicts the disease severity score against the median number of HbF modulating alleles in the SCA patients. The patients with higher number of modulating alleles showed significant positive correlation with the HbF levels (mean HbF: $21.9 \% \pm 9.8$ ) as compared to the other patient group. (B) Kaplan Meier transfusion free survival curve was plotted considering all the genetic modifiers ( $\alpha$-thalassemia and the HbF modifiers) and a delayed median age of presentation in patients with more number of modifying alleles: 72 months was observed as compared to the other group: 48 months (P: 0.02, Gehan Breslow Wilcoxon test). (C) Depicts the disease severity score (DSS) against the number of $\mathrm{HbF}$ modulating alleles in the $\beta$-thalassemia intermedia patients. The patients inheriting more number of the disease ameliorating alleles showed elevated HbF levels (mean HbF: 75.1\% \pm 29.9 ), with reduced disease severity score (mean DSS: 5.6) as compared to the patients in the other group (P: 0.08). (D) Kaplan-Meier transfusion free survival curve analysis (considering both primary and secondary modifiers) showing slight delay in median age of presentation in patients with more number of modifying alleles (38.5 months) as compared to group (36.0 months) (P: 0.36, Gehan Breslow Wilcoxon test).

patients [P: 0.004, Odds Ratio 8.6 (95\% CI 1.9-37.9)]. However, Garewal et al. ${ }^{20}$ described that, in majority of the Indian patients, the beta genotype alone cannot predict the clinical phenotype of the patients ${ }^{20}$. A similar observation was seen in our patients, which suggested the presence of other genetic factors that may play a synergistic role in modifying the disease severity of $\beta$-thalassemia. In a previous study by Nadkarni et al. ${ }^{21}$, the associated $\alpha$-thalassemia was found to be significantly higher in the thalassemia intermedia group (37\%) as compared to $\beta$-thalassemia major group $(5 \%)(\mathrm{P}<0.025)^{21}$. A study by Pandey et al. ${ }^{22}$ revealed $32 \%$ sickle cell anemia patients with co-existing $\alpha$-globin gene deletion, showed a relatively milder clinical course with improved hematological indices and reduced transfusion history ${ }^{22}$. Similarly, Rumaney et al..$^{23}$ observed that in Cameroon sickle cell disease patients, co-inheritance of $\alpha$-thalassemia showed improved hematological indices with a better survival rate ${ }^{23}$. Similarly in this study, we observed that the coinheritance of $\alpha$-thalassemia was higher in the milder $\beta$-thalassemia patient group as compared to the other group. $51 \%$ of SCA patients also showed presence of $\alpha$-thalassemia. Alternatively, the excess alpha-globin chains play a significant role in the pathophysiology of homozygous beta-thalassaemia. The coexistence of a triplicated $\alpha$-globin gene is found to be exacerbating the phenotypic severity of $\beta$-thalassemia by causing more globin chain imbalance, thus causing severe anemia ${ }^{24}$.

The effect of the genetic modifiers of fetal hemoglobin was also analysed in this study. A study in the Egyptian $\beta$-thalassemia patients showed that $83.3 \%$ of $\beta$-thalassemia intermedia cases were heterozygous for XmnI 
polymorphism as compared to $\beta$-thalassemia major (57.6\%) and that $\beta$-thalassemia intermedia with single $\mathrm{T}$ allele of XmnI showed delayed age of diagnosis, raised $\mathrm{HbF}$ levels and milder disease phenotype as compared patients negative for the XmnI polymorphism ${ }^{25}$. In another study, it was also determined that the patients with homozygosity for the mutant $\mathrm{T}$ allele of XmnI polymorphism significantly showed higher mean $\mathrm{HbF}$ levels $(85.5 \pm 6.8 \%)$ as compared to the thalassemia intermedia patients homozygous for XmnI CC genotype $(19.5 \% \pm 29.3)^{26}$. A similar result was observed in our patient group where in the $\beta$-thalassemia intermedia patients homozygous for variant allele $\mathrm{T}$ showed significantly higher $\mathrm{HbF}$ level.

$+25 \mathrm{G} \rightarrow$ A polymorphism in ${ }^{\mathrm{A}} \gamma$-globin promoter region was found to be significantly associated with elevated $\mathrm{HbF}$ levels in the $\beta$-thalassemia intermedia group. This polymorphism was first reported by Bianchi et al. ${ }^{27}$ and a strong linkage of this polymorphism with the $-158 \mathrm{C} \rightarrow \mathrm{T}(\mathrm{XmnI}$ polymorphism) was observed in their study as well ${ }^{27}$. It has been reported that $+25 \mathrm{G} \rightarrow \mathrm{A}$ polymorphism reduces the binding efficacy of LYAR transcription factor (repressor of $\gamma$-globin gene expression) and abolishes the binding of 2 negative epigenetic regulators [DNA methyltransferase 3 alpha (DNMT3A) and protein arginine methyltransferase 5 (PRMT5)] to this promoter region $^{27,28}$. Thus, it could be speculated that there could be a cumulative effect of mutant alleles of both XmnI polymorphism ( $\mathrm{T}$ allele) and $+25 \mathrm{G} \rightarrow$ A polymorphism (A allele) in synergistically elevating the HbF levels.

The association of BCL11A polymorphisms with elevated HbF levels and their effect on amelioration of the disease phenotype was studied by Uda et al. ${ }^{29}$ in Sardinian $\beta$-thalassemia homozygous patients ${ }^{29}$. They showed that the mutant $\mathrm{C}$ allele of $\mathrm{rs} 11886868(\mathrm{C} \rightarrow \mathrm{T})$ formed the major allele in Sardinian population and was significantly associated with elevated $\mathrm{HbF}$ levels in $\beta$-thalassemia intermedia patient group. Similarly, in Indian patients Dadheech et al. ${ }^{30}$, determined that the $\mathrm{C}$ allele was significantly associated with the raised HbF levels and delayed the age of presentation in both thalassemia homozygous and SCA groups ${ }^{30}$. In our study, the mutant CC genotype was found to be significantly associated with $\mathrm{HbF}$ levels only in the sickle cell anemia patients.

Similarly, in Indonesian HbE- $\beta$-thalassemia patients inheriting variant alleles of rs 11886868 , rs766432 in the $B C L 11 A$ gene, showed higher HbF levels and reduced disease severity as compared to patients with wild type alleles ${ }^{31}$. The second SNP that was found to be significantly associated with the HbF levels is rs 1427407 $(\mathrm{G} \rightarrow \mathrm{T})$ polymorphism in the $B C L 11 A$ gene. Our results were found to be consistent with the earlier report by Bhanushali et al. ${ }^{32}$, who showed a similar distribution of allelic frequency of rs1427407 in Indian SCA patients ${ }^{32}$. Studies have demonstrated that the patients with the mutant $\mathrm{T}$ allele of $\mathrm{rs} 1427407(\mathrm{G} \rightarrow \mathrm{T})$ showed significantly higher $\mathrm{HbF}$ level, the results of which are concordant with our study, thus suggesting a crucial role of this SNP in modulating the $\mathrm{HbF}$ levels ${ }^{32,33}$.

Similarly, Chaouch et al. ${ }^{34}$ observed that co inheritance of the mutant C allele of the rs11886868 and the mutant A allele of the rs46713939 ameliorated the clinical phenotype of SCA patients ${ }^{34}$. In our study, though the A allele of rs46713939 was found to be higher in the TI group, no significant difference in the allelic frequencies among the milder and severe groups could be observed. Studies have identified a restricted $14 \mathrm{~kb}$ region in BCL11A intron 2 to be associated with H3-acetylation, RNA pol II activity as well as a strong GATA-I, TAL-1 binding site, all of which indicated the presence of a regulatory sequence in this region ${ }^{35,36}$. Thus, suggesting that the presence of a polymorphism could potentially alter the recruitment of transcription factors to this region.

Similarly, in our population, a 100\% linkage was observed between rs66650371 and rs9399137 polymorphism. A similar observation was seen in the Tanzanian SCD patients where, both these polymorphisms in HMIP 2A block were strongly associated with $\mathrm{HbF}$ levels and showed a strong linkage ${ }^{37}$. Similarly, Lai et al. ${ }^{38}$ in $\beta$-thalassemia intermedia patients showed that the mutant alleles of rs9376090 (NC_000006.12:g.1350900 90T > C), rs7776054 (NC_000006.12:g.135097778A > G), rs9399137, rs9389268 (NC_000006.12:g.135098493 A > G), rs9402685 (NC_000006.12:g.135098550T > C) in the HbS1L-MYB intergenic region and rs189984760 in the BCL11A locus, showed significant association with high $\mathrm{HbF}_{\text {level }}{ }^{38}$. Bioinformatic characterization of the 3 bp deletion polymorphism showed that this region acts as a binding site for 4 transcription factors TAL1/ SCL, E47, GATA-2 and RUNX1/ AML1 all of which are important for erythroid differentiation, erythropoiesis and the presence of the mutant allele may disrupt the MYB gene expression, which is a negative regulator of the $\gamma$-globin gene expression ${ }^{39,40}$.

In our study, it was observed that in SCA patients, the prevalence of the T allele of $\operatorname{rs} 1427407(\mathrm{G} \rightarrow \mathrm{T})$ and the $3 \mathrm{bp}$ deletional allele of rs66650371 both were significantly higher in the SCA patient group possessing higher $\mathrm{HbF}$ levels $(\mathrm{HbF}>17.4 \%)$ as compared to the SCA patients, with lower $\mathrm{HbF}$ level ( $\mathrm{HbF} \leq 17.4 \%)$. A similar result was shown by Adeyemo et al. ${ }^{41}$, where in patients with the mutant alleles of these 2 polymorphisms had a milder form of the disease, with improved hemoglobin levels ${ }^{41}$.

Similarly, in $\beta$-thalassemia homozygous patients, the cumulative effect of $3 \mathrm{HbF}$ associated mutant alleles of the SNPs $-158(\mathrm{C} \rightarrow \mathrm{T})$, rs11886868 $(\mathrm{C} \rightarrow \mathrm{T})$ and $\mathrm{rs} 1427407(\mathrm{G} \rightarrow \mathrm{T})$, were observed significantly in the $\beta$-thalassemia intermedia group as compared to $\beta$-thalassemia major group. A comparable result was reported by Allawi et al. $^{42}$, where they determined the main factors leading to milder phenotypes were the attenuated $\beta$-thalassemia alleles, the T allele of XmnI polymorphism and the minor allele of BCL11A rs $10189857^{42}$. Cardoso et al. ${ }^{43}$, studied the influence of three known major loci on the HbF trait (HBG2, rs748214; BCL11A, rs4671393; and HBS1L-MYB, rs28384513, rs489544 and rs9399137) in north Brazilian SCA patients and they showed that the raised $\mathrm{HbF}$ trait was primarily influenced by mutant alleles of $\mathrm{BCL}_{11} \mathrm{~A}^{43}$.

Further to predict the disease severity in presence of these genetic modifiers, Badens et al. ${ }^{5}$ studied 5 genetic modifiers of $\beta$-thalassemia. By regression analysis, all 5 types of favorable allele were found to be significantly associated with thalassemia intermedia phenotype. The $\beta$-globin gene mutations and XmnI polymorphism were the most influential modifiers of the disease severity ${ }^{5}$. A similar observation was reported by Danjou et al. ${ }^{44}$, wherein they further evaluated the age of the first transfusion with respect to the inheritance of HbF boosting alleles and observed that the age of transfusion was found to be delayed in presence of more number of $\mathrm{HbF}$ inducing alleles ${ }^{44}$. Similarly, in our study, it was observed that, $8 \%$ of thalassemia intermedia patients (HbF: $82.7 \% \pm 22.6$ ) had inherited more than 10 disease ameliorating alleles as compared to none in thalassemia major 
patients. Thalassemia major patients (64\%) showed less number of disease modifying alleles as compared to the thalassemia intermedia patients (36\%). Similarly, in SCA patients, the ameliorating alleles was found to be higher in the raised $\mathrm{HbF}$ group $(\mathrm{HbF}>17.4)(31.3 \%)$ (mean $\mathrm{HbF}: 26.2 \% \pm 8.3)$ as compared to patients in low $\mathrm{HbF}$ group $(\mathrm{HbF} \leq 17.4 \%)(4 \%)$ (mean $\mathrm{HbF}: 12.1 \% \pm 3.5)$.

These observations suggest that the presence of increased number of an ameliorating allele, may help in reducing the disease severity in hemoglobinopathy patients mainly by restoring the globin chain imbalance. The precise identification of the polymorphisms associated with elevated HbF levels may help in developing a molecular chip that may assist in predicting the disease severity. Validation of our results needs to be carried out in a bigger cohort.

\section{Conclusions}

The present study expands the knowledge of the frequency of the genetic modifiers (primary and secondary modifiers) and the independent effect of individual predictor genes on HbF levels in hemoglobinopathy patients. The analysis of the cumulative effect of the HbF modulators may help in identifying the strongest response gene to the $\mathrm{HbF}$ level in both $\beta$-thalassemia and sickle cell anemia patients in the population. The predictions based on genetic modifiers thus can foresee the severity of $\beta$-thalassemia and SCA. This study may assist the clinicians, to predict the clinical phenotype of hemoglobinopathy patients at an early stage and thus may help in the efficient management of the disease. This may contribute towards molecular mechanisms of HbF regulation and the development of therapeutic approaches for $\beta$-hemoglobinopathies.

Received: 28 February 2021; Accepted: 2 September 2021

Published online: 22 October 2021

\section{References}

1. Balgir, R. The burden of haemoglobinopathies in India and the challenges ahead. Curr. Sci. 79, 1536-1547 (2000).

2. Thein, S. The molecular basis of $\beta$-thalassemia. Cold Spring Harb. Perspect. Med. 3, a011700. https://doi.org/10.1101/cshperspect. a011700 (2013).

3. Steinberg, M. \& Sebastiani, P. Genetic modifiers of sickle cell disease. Am. J. Hematol. 87, 795-803. https://doi.org/10.1002/ajh. $23232(2012)$.

4. Thein, S. Genetic basis and genetic modifiers of $\beta$-thalassemia and sickle cell disease. Adv. Exp. Med. Biol. 1013, 27-57. https:// doi.org/10.1007/978-1-4939-7299-9_2 (2017).

5. Badens, C. et al. Variants in genetic modifiers of $\beta$-thalassemia can help to predict the major or intermedia type of the disease. Haematologica 96, 1712-1714. https://doi.org/10.3324/haematol.2011.046748 (2011).

6. Nadkarni, A. et al. The phenotypic and molecular diversity of hemoglobinopathies in India: A review of 15 years at a referral center. Int. J. Lab. Hematol. 41, 218-226. https://doi.org/10.1111/ijlh.12948 (2019).

7. Tan, A., Quah, T., Low, P. \& Chong, S. A rapid and reliable 7-deletion multiplex polymerase chain reaction assay for alphathalassemia. Blood 98, 250-251. https://doi.org/10.1182/blood.v98.1.250 (2001).

8. Kim, S. \& Misra, A. SNP genotyping: Technologies and biomedical applications. Annu. Rev. Biomed. Eng. 9, 289-320. https://doi. org/10.1146/annurev.bioeng.9.060906.152037 (2007).

9. Nadkarni, A., Gorakshakar, A., Colah, R., Mohanty, D. \& Ghosh, K. Evaluation of the clinical severity of $\beta$ thalassemia homozygous patients using a phenotypic scoring system. J. Chin. Clin. Med. 2, 8 (2007).

10. Italia, K. et al. Hydroxyurea in sickle cell disease-A study of clinico-pharmacological efficacy in the Indian haplotype. Blood Cells Mol. Dis. 42, 25-31. https://doi.org/10.1016/j.bcmd.2008.08.003 (2009).

11. Hariharan, P., Colah, R., Ghosh, K. \& Nadkarni, A. Differential role of Kruppel like factor 1 (KLF1) gene in red blood cell disorders. Genomics 111, 1771-1776. https://doi.org/10.1016/j.ygeno.2018.11.032 (2019).

12. Taher, A., Ismảeel, H. \& Cappellini, M. Thalassemia intermedia: Revisited. Blood Cells Mol. Dis. 37, 12-20. https://doi.org/10. 1016/j.bcmd.2006.04.005 (2006).

13. Modell, B. \& Berdoukas, V. The Clinical Approach to Thalassemia Vol. 171 (Grune and Stratton, 1984).

14. Trehan, A., Sharma, N., Das, R., Bansal, D. \& Marwaha, R. Clinico investigational and demographic profile of children with thalassemia major. Indian J. Hematol. Blood Transfus. 31, 121-126. https://doi.org/10.1007/s12288-014-0388-y (2015).

15. Musallam, K., Taher, A. \& Rachmilewitz, E. $\beta$-Thalassemia intermedia: A clinical perspective. Cold Spring Harb. Perspect. Med. 2, a013482. https://doi.org/10.1101/cshperspect.a013482 (2012).

16. Mpalampa, L., Ndugwa, C., Ddungu, H. \& Idro, R. Foetal haemoglobin and disease severity in sickle cell anaemia patients in Kampala, Uganda. BMC Blood Disord. 12, 11. https://doi.org/10.1186/1471-2326-12-11 (2012).

17. Nayak, S., Motwani, N., Dewangan, M. \& Jai, A. Clinical and haematological profile of children with sickle cell anaemia admitted to a rural medical college of Chhattisgarh. India. Int. J. Contemp. Pediatr. 5, 173-177. https://doi.org/10.18203/2349-3291.ijcp2 0175581 (2018).

18. Mukherjee, M. et al. $\alpha$-Thalassemia on sickle-cell anemia linked to the Arab-Indian haplotype in India. Am. J. Hematol. 55, 104-109. https://doi.org/10.1002/(sici)1096-8652(199706)55:2\%3c104::aid-ajh9\%3e3.0.co;2-x (1997).

19. Colah, R. et al. Impact of beta globin gene mutations on the clinical phenotype of beta thalassemia in India. Blood Cells Mol. Dis. 33, 153-157. https://doi.org/10.1016/j.bcmd.2004.05.002 (2004).

20. Garewal, G., Das, R., Awasthi, A., Ahluwalia, J. \& Marwaha, R. The clinical significance of the spectrum of interactions of CAP+1 $(\mathrm{A} \rightarrow \mathrm{C})$, a silent beta-globin gene mutation, with other beta-thalassemia mutations and globin gene modifiers in north Indians. Eur. J. Haematol. 79, 417-421. https://doi.org/10.1111/j.1600-0609.2007.00958.x (2007).

21. Nadkarni, A. et al. Molecular pathogenesis and clinical variability of beta-thalassaemia syndromes among Indians. Am. J. Hematol. 68, 75-80. https://doi.org/10.1002/ajh.1156 (2001).

22. Pandey, S., Pandey, S., Mishra, R., Sharma, M. \& Saxena, R. Genotypic influence of $\alpha$-deletions on the phenotype of Indian sickle cell anemia patients. Korean J. Hematol. 46, 192-195. https://doi.org/10.5045/kjh.2011.46.3.192 (2011).

23. Rumaney, M. et al. The co-inheritance of alpha-thalassemia and sickle cell anemia is associated with better hematological indices and lower consultations rate in Cameroonian patients and could improve their survival. PLoS One 9, e100516. https://doi.org/10. 1371/journal.pone.0100516 (2014).

24. Mehta, P. et al. Diverse phenotypes and transfusion requirements due to interaction of $\beta$ thalassaemias with triplicated aglobin genes. Ann. Hematol. 94, 1953-1958. https://doi.org/10.1007/s00277-015-2479-8 (2015).

25. Said, F. \& Abdel-Salam, A. XmnI polymorphism: Relation to $\beta$ thalassemia phenotype and genotype in Egyptian Children. Egypt J. Med. Hum. Genet. 16, 123-127. https://doi.org/10.1016/j.ejmhg.2014.12.005 (2015). 
26. Miri-Moghaddam, E., Bahrami, S., Naderi, M., Bazi, A. \& Karimipoor, M. Xmn1-158 $\gamma$ G variant in $\beta$-thalassemia intermediate patients in South-East of Iran. Int. J. Hematol. Oncol. Stem Cell Res. 11, 165-171 (2017).

27. Bianchi, N. et al. Structural and functional insights on an uncharacterized A $\gamma$-globin-gene polymorphism present in four $\beta 0$-thalassemia families with high fetal hemoglobin levels. Mol. Diagn. Ther. 20, 161-173. https://doi.org/10.1007/s40291-0160187-2 (2016).

28. Chen, D. et al. A genetic variant ameliorates $\beta$-thalassemia severity by epigenetic-mediated elevation of human fetal hemoglobin expression. Am. J. Hum. Genet. 101, 130-138. https://doi.org/10.1016/j.ajhg.2017.05.012 (2017).

29. Uda, M. et al. Genome-wide association study shows BCL11A associated with persistent foetal haemoglobin and amelioration of the phenotype of $\beta$-thalassaemia. Proc. Natl. Acad. Sci. U. S. A. 105, 1620-1625. https://doi.org/10.1073/pnas.0711566105 (2008).

30. Dadheech, S. et al. Association of BCL11A genetic variant (rs11886868) with severity in $\beta$-thalassaemia major \& sickle cell anaemia. Indian J. Med. Res. 143, 449-454. https://doi.org/10.4103/0971-5916.184285 (2016).

31. Rujito, L. et al. Modifying effect of XmnI, BCL11A, and HBS1L-MYB on clinical appearances: A study on $\beta$-thalassemia and hemoglobin E/ $\beta$-thalassemia patients in Indonesia. Hematol. Oncol. Stem Cell Ther. 9, 55-63. https://doi.org/10.1016/j.hemonc. 2016.02.003 (2016).

32. Bhanushali, A., Patra, P., Nair, D., Verma, H. \& Das, B. Genetic variant in the BCL11A (rs1427407), but not HBS1-MYB (rs6934903) loci associate with fetal hemoglobin levels in Indian sickle cell disease patients. Blood Cells Mol. Dis. 54, 4-8. https://doi.org/10. 1016/j.bcmd.2014.10.003 (2015).

33. Sebastiani, P. et al. BCL11A enhancer haplotypes and fetal hemoglobin in sickle cell anemia. Blood Cells Mol. Dis. 54, 224-230. https://doi.org/10.1016/j.bcmd.2015.01.001 (2015).

34. Chaouch, L. et al. rs11886868 and rs4671393 of BCL11A associated with HbF level variation and modulate clinical events among sickle cell anemia patients. Hematology 3, 1-5. https://doi.org/10.1179/1607845415Y.0000000026 (2016).

35. Jawaid, K., Wahlberg, K., Thein, S. \& Best, S. Binding patterns of BCL11A in the globin and GATA1 loci and characterization of the BCL11A fetal hemoglobin locus. Blood Cells Mol. Dis. 45, 140-146. https://doi.org/10.1016/j.bcmd.2010.05.006 (2010).

36. Liu, L. et al. Original research: A case-control genome-wide association study identifies genetic modifiers of fetal hemoglobin in sickle cell disease. Exp. Biol. Med. (Maywood). 241, 706-718. https://doi.org/10.1177/1535370216642047 (2016).

37. Mtatiro, S. et al. Genetic association of fetal-hemoglobin levels in individuals with sickle cell disease in Tanzania maps to conserved regulatory elements within the MYB core enhancer. BMC Med. Genet. 16, 4. https://doi.org/10.1186/s12881-015-0148-3 (2015).

38. Lai, Y. et al. Genetic variants at BCL11A and HBS1L-MYB loci influence Hb F levels in Chinese Zhuang $\beta$-thalassemia intermedia patients. Hemoglobin 40, 405-410. https://doi.org/10.1016/j.bcmd.2017.01.011 (2016).

39. Farrell, J. et al. A 3-bp deletion in the HBS1L-MYB intergenic region on chromosome $6 \mathrm{q} 23$ is associated with HbF expression. Blood 117, 4935-4945. https://doi.org/10.1182/blood-2010-11-317081 (2011).

40. Stadhouders, R. et al. HBS1L-MYB intergenic variants modulate foetal haemoglobin via long-range MYB enhancers. J. Clin. Investig. 124, 1699-1710. https://doi.org/10.1172/JCI71520 (2014).

41. Adeyemo, T. et al. A survey of genetic fetal-haemoglobin modifiers in Nigerian patients with sickle cell anaemia. PLoS One 13, e0197927. https://doi.org/10.1371/journal.pone.0197927 (2018).

42. Al-Allawi, N., Puehringer, H., Raheem, R. \& Oberkanins, C. Genetic modifiers in $\beta$-thalassemia intermedia: A study on 102 Iraqi Arab patients. Genet. Test Mol. Biomark. 19, 242-247. https://doi.org/10.1089/gtmb.2014.0310 (2015).

43. Cardoso, G. et al. DNA polymorphisms at BCL11A, HBS1L-MYB and Xmn1-HBG2 site loci associated with fetal hemoglobin levels in sickle cell anemia patients from Northern Brazil. Blood Cells Mol. Dis. 53, 176-179. https://doi.org/10.1016/j.bcmd.2014. 07.006 (2014).

44. Danjou, F. et al. Genetic modifiers of $\beta$-thalassemia and clinical severity as assessed by age at first transfusion. Haematologica 97, 989-993. https://doi.org/10.3324/haematol.2011.053504 (2012).

\section{Acknowledgements}

We thank the individuals for participating in the study. We also thank University of Mumbai for their support.

\section{Author contributions}

P.H.: Laboratory work and wrote the manuscript. M.G., P.S., P.M.: Laboratory work and data collection. A.N.: Designed the research study and edited the manuscript.

\section{Funding}

This work was funded by Indian Council of Medical Research (ICMR).

\section{Competing interests}

The authors declare no competing interests.

\section{Additional information}

Supplementary Information The online version contains supplementary material available at https://doi.org/ 10.1038/s41598-021-00169-x.

Correspondence and requests for materials should be addressed to A.N.

Reprints and permissions information is available at www.nature.com/reprints.

Publisher's note Springer Nature remains neutral with regard to jurisdictional claims in published maps and institutional affiliations.

Open Access This article is licensed under a Creative Commons Attribution 4.0 International License, which permits use, sharing, adaptation, distribution and reproduction in any medium or format, as long as you give appropriate credit to the original author(s) and the source, provide a link to the Creative Commons licence, and indicate if changes were made. The images or other third party material in this article are included in the article's Creative Commons licence, unless indicated otherwise in a credit line to the material. If material is not included in the article's Creative Commons licence and your intended use is not permitted by statutory regulation or exceeds the permitted use, you will need to obtain permission directly from the copyright holder. To view a copy of this licence, visit http://creativecommons.org/licenses/by/4.0/.

(c) The Author(s) 2021 